\title{
Right atrial metastatic endometrial adenocarcinoma - case report
}

\author{
Vlatka Rešković Lukšić*, Kristina Marić Bešić, Nikša Drinković Jr, Maja Strozzi, Borislav Belev, \\ Bojan Biočina, Jadranka Šeparović Hanževački, Nikša Drinković \\ University Hospital Center Zagreb, Zagreb, Croatia
}

\begin{abstract}
A 68-year old female patient known for stable coronary artery disease was referred for a preoperative examination before elective parathyreoidectomy. Transthoracic echocardiographic (TTE) examination revealed a right atrium mass $(2,6 \times 3,0 \mathrm{~cm})$. She had a history of multiple tumors: gastric polypectomy of neuronedocrine tumor one year ago; endometrial carcinoma treated operatively and with brachytherapy nine months ago; adrenal adenoma and parathyreoid adenoma were known and also thyroid multinodular goiter with hyperthyreoidism. But since the patient also had a deep vein thrombosis six months ago and was not adequately anticoagulated, warfarin therapy was introduced and MSCT confirmed thrombus characteristics of the mass. After four weeks follow-up echocardiography there were no changes in mass dimensions. One day before planned reevaluation, she was admitted for superior vena cava syndrome. TTE confirmed infiltration of the superior vena cava and almost entire cavity of the right atrium by irregular mass $(4,3 \times 3,8$ $\mathrm{cm}$ ) while tricuspid valve inflow was not compromised; control MSCT confirmed diagnosis. The patient was presented to cardiac surgeon and excision of the tumor and part of right atrial free wall was performed, PHD has shown me-
\end{abstract}

tastatic adenocarcinoma. The patient was referred to an oncologist and during further evaluation the metastasis of the endometrial adenocarcinoma was confirmed. PET/CT with F-18FDG showed metastatic mediastinal lymph nodes.

Endometrial adenocarcinoma rarely metastasizes to the heart, there are only few cases described in the literature. In our patient, the metastasis was rapidly progressive, and a history of more than one previous tumor made the diagnosis more difficult. A multidisciplinary approach in cases like this one is mandatory to successfully diagnose and treat such patients.

KEYWORDS: echocardiography, cardiac tumors, endometrial adenocarcinoma, superior vena cava syndrome.

\section{Received: $20^{\text {th }}$ Mar 2013}

*Address for correspondence: Klinički bolnički centar Zagreb, Kišpatićeva 12, HR-10000 Zagreb, Croatia.

Phone: +385-1-2388-888

E-mail: vlatka.reskovic@gmail.com

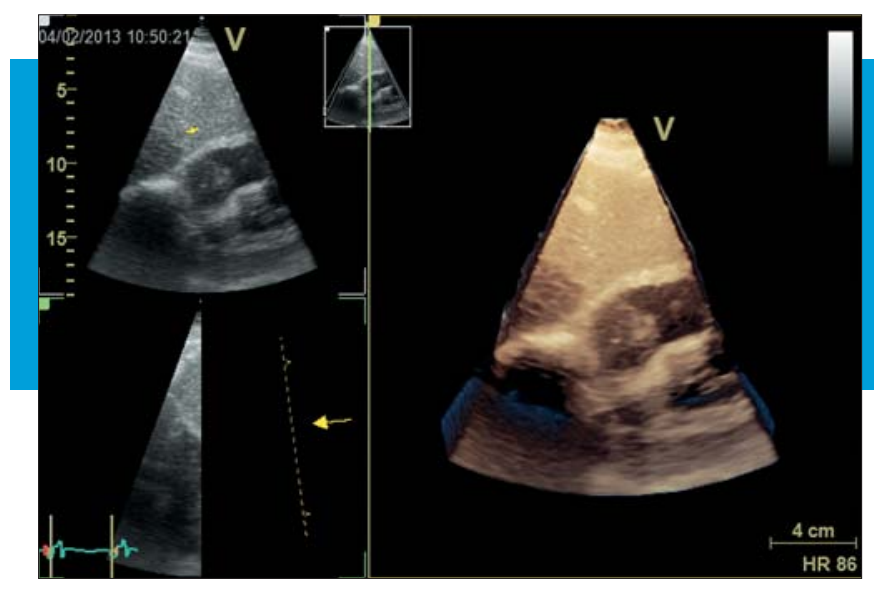

Figure 2. The four-chamber view with right atrium mass.
Figure 1. Transthoracic three-dimensional echocardiography subcostal view of right atrium tumor.

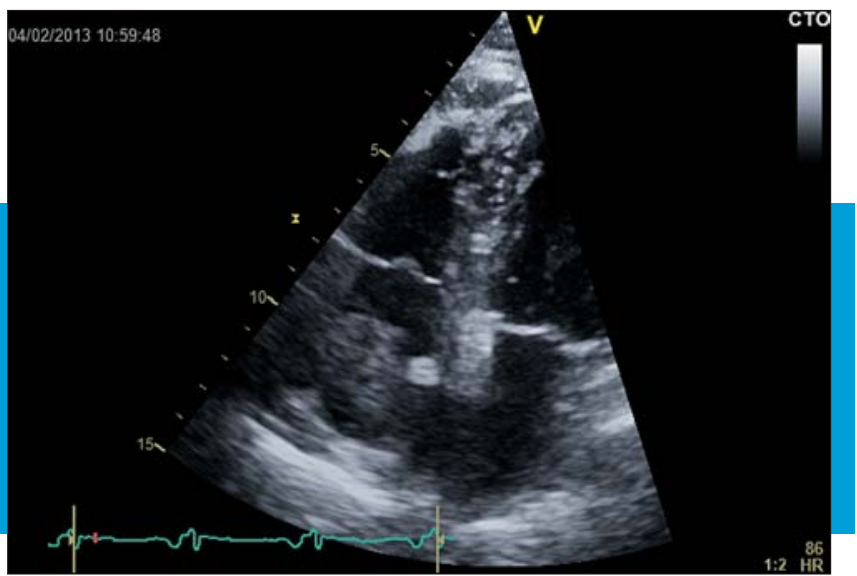



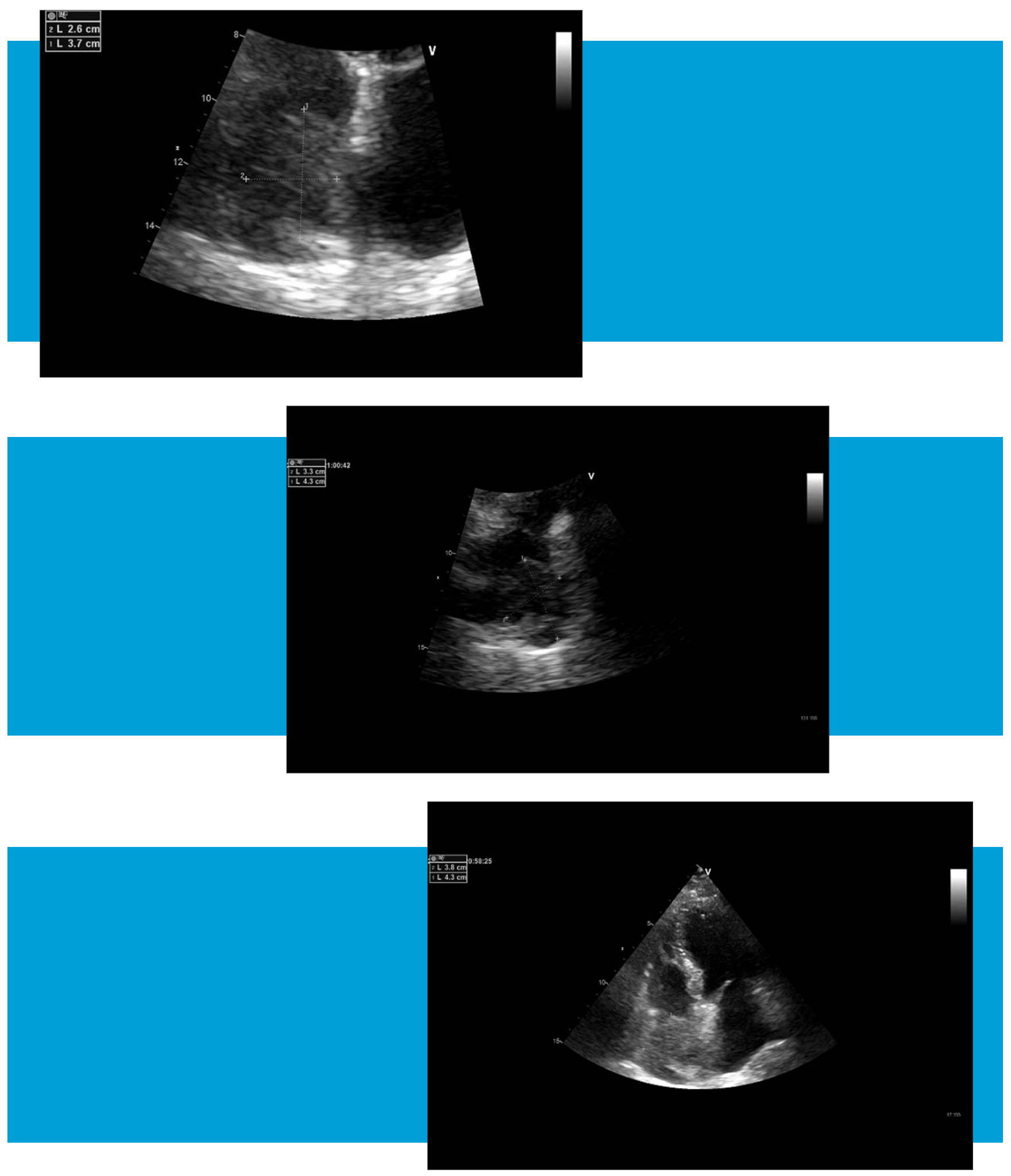

Figure 3. Dimensions of the tumor from different views $(\boldsymbol{A}-\boldsymbol{C})$.

\section{Literature}

1. Arvold DS. Right ventricular metastasis of endometrial carcinoma: a case report. Gynecol Oncol. 1988;29(2):231-3.

2. Castillo-Sang M, Slam K, Gociman B, Durham SJ, Booth R. Endometrial adenocarcinoma metastatic to the right ventricle: a case report and review of the literature. Cardiovasc Pathol. 2009;18(3):178-82.

3. Bigsby GE 4th, Holloway RW, Weppelman B, Reynolds RB, Williams B. Endometroid adenocarcinoma of the uterus with cardiac metastasis. A case report and six-year followup. Gynecol Oncol. 2005;97(1):256-9.

4. Bussani R, De-Giorgio F, Abbate A, Silvestri F. Cardiac metastases. J Clin Pathol. 2007;60(1):27-34. 